\title{
La imagen, la cultura y la política en el proceso electoral extraordinario 2020 en Arequipa Perú
}

The image, culture and politics in the extraordinary electoral process in Arequipa Peru

Gregorio Nicolás Cusihuamán Sisa ${ }^{1}$

Carlos llich Aguilar Del Carpio 2

Javier Guido Alarcón Condori 3

RECIBIDO: 9 DE ABRIL DE 2020

ACEPTADO: 5 DE JUNIO DE 2020

\section{RESUMEN}

La investigación realizada examina el símbolo, la cultura política, así como la imagen de los candidatos y partidos políticos en el proceso electoral extraordinario al Congreso de la Republica, realizado en enero del presente año en Perú; lo hace desde una perspectiva de la comunicación política. El objetivo es demostrar el nivel

\footnotetext{
Doctor en Ciencias sociales, Maestro en Economía, Relacionista industrial y público, economista, Docente, Universidad Nacional de San Agustín de Arequipa, Perú; gcusihuaman@unsa.edu.pe,

ORCID: https://orcid.org/0000-0002-0568-8065 Google Scholar: https://url2.cl/REjR†

2 Doctor en Comunicación y Desarrollo, Maestro en Ciencias: Educación, Periodista, Docente, Universidad Nacional de San Agustín de Arequipa, Perú; caguilarde@unsa.edu.pe,

ORCID: https://orcid.org/0000-0001-8749-2228

3 Maestro en Ciencias, Licenciado en Relaciones Industriales y Públicas, Docente, Universidad Nacional de San Agustín de Arequipa, Perú; jalarconc@unsa.edu.pe,

ORCID: https://orcid.org/0000-0001-9195-8756
}

Socialium revista científica de Ciencias Sociales, Vol 4 - No. 2, julio - diciembre 2020, pág. 193-218.

DOI https://doi.org/10.26490/uncp.sl.2020.4.2.677 


\section{4}

de articulación de los factores que construyen una sociedad democrática en un proceso electoral, reconociendo que las relaciones entre cultura y política tienen larga data, sin embargo, los niveles de articulación en el lenguaje político tienen su expresión en la imagen que proyectan a la sociedad, siendo esa la razón fundamental del artículo. La metodología descriptiva aplicada combina técnicas de análisis de formatos de observación de la imagen con entrevistas Delphi, generando resultados cuali-cuantitativos. Las conclusiones muestran una desarticulación de elementos concomitantes en la consolidación del orden político democrático, la percepción de una mono-cultura encaminada a resolver la coyuntura sin perspectiva de largo plazo, la desideologización de las organizaciones políticas y el predominio de la imagen del "líder" sobre la del partido es una constante que debilita el fortalecimiento institucional de las organizaciones políticas.

Palabras clave: imagen, símbolo, cultura política, procesos electorales, lenguaje político

\section{ABSTRACT}

The investigation examines the culture, politics, and image of political parties in the extraordinary electoral process for Congress, held in January of this year in Peru; from a political communication perspective. The objective is to demonstrate the level of articulation of the factors that build a democratic society in an electoral process, the relations between culture and politics have a long history, however, the levels of articulation in political language have their expression in the image they project to society, that being the fundamental reason for the article. The applied descriptive methodology combines techniques for analyzing image observation formats with interviews, generating qualitative and quantitative results. The conclusions show a disarticulation of concomitant elements in the consolidation of the democratic political order, the perception of a mono-culture aimed at solving the situation without prospective, the de-ideologization of political organizations and the predominance of the image of the "leader" over that of the "leader". Party is a constant that degenerates the institutional strengthening of political organizations.

Keywords: image, culture, politics, electoral processes, political language 


\section{Introducción}

La profesionalización de los expertos en el ámbito electoral es cada vez más significativo, el último proceso realizado en nuestro país nos ha llevado a una serie de conjeturas sobre el manejo de la imagen institucional del partido así como la imagen individual del candidato, a su vez la articulación con la cultura política de nuestra sociedad nos permite evaluar el proceso desde una perspectiva de la comunicación política y el manejo del capital simbólico, como elemento trascendente en el presente análisis.

Reconociendo que el trabajo científico en esta área del conocimiento es precario e insuficiente o como lo señala Bunker y Bauchowitz, (2016): "El pronóstico electoral y el seguimiento de la opinión pública se encuentran en un estado incipiente en América" (pág. 209), y que muchas veces al margen de instituciones académicas que tengan vínculo con el desarrollo del estudio de la imagen y la cultura política, ello se evidencia en que - aun - la bibliografía - sobre estos temas - es escasa. A su vez, Pérez (2018) agrega que los procesos electorales se fundamentan en la voluntad, la confianza y la libertad de elección, procedimiento que justifica su obligatoriedad y legitimidad (pág. 582), fortaleciendo el capital simbólico en la medida que genera una estructura legítima de poder.

Los procesos electorales requieren legitimidad durante el desarrollo de los mismos, sin embargo este requisito tiene dos componentes - en el análisis de Myers (2013) - un componente en la actitud de los perdedores de la elección, así como el capital social. El primero refiere al impacto que ocasiona el proceso electoral, en tres esferas; la estabilidad del gobierno ganador, la legitimidad de las instituciones electorales y las posibilidades futuras de los perdedores (Myers, 2013). A su vez, De la O en un análisis planteado por Bourdieu (1993), Putnam (2000) y Coleman (1997), refiere al capital social como aquellas reciprocidades materiales y simbólicas que existen y circulan en una red social, o bien como la capacidad de acción colectiva; y que la falla de esta genera escenarios negativos como la falta de comunicación y coordinación de los representados, que a la postre conduce a la propensión del político al control del electorado (De la O, 2013). 


\section{6}

La cultura política es un componente natural que viene alimentado por la capacidad del capital simbólico legitimado en un proceso electoral reconociendo que "es el imaginario social unido a los estímulos mediáticos lo que hizo reaccionar a una colectividad direccionada de acuerdo con determinados fines" (Soní-Soto, 2011 , pág. 68). En suma consideramos que es la interacción entre el colectivo social con la acción mediática la que determina el resultado electoral.

Asimismo en el trabajo podemos evidenciar un aspecto relevante en la vida política peruana que es la debilidad en la institucionalización de los partidos políticos, e históricamente los procesos electorales en el país siempre han respondido a este problema, que lejos de construir una clase política y dirigente sólida, solo han sido las agrupaciones políticas que se han organizado de forma coyuntural las que han dado vida a los procesos eleccionarios. Así en un tratado interesante de la Política en el Perú del siglo XX dice: "Es difícil hablar de un sistema de partidos políticos -concepto que se refiere al conjunto de estos- así como de su capacidad representativa y de la relativa estabilidad del sistema" (Pease y Romero, 2013, pág. 432). Por su parte Sartori (2011) señala que:"... los procesos electorales son un método de reclutamiento del personal que irá a ocupar puestos políticos; de donde se deduce que son parte integrante de los procesos verticales del sistema político" (pág. 91). Podemos reconocer que aún estamos lejos de haber consolidado sistema moderno de partidos políticos en el Perú.

En otra perspectiva de análisis del proceso electoral, Trad y Ibinarriaga (2010) señalan que este es, "un lugar donde lo real y lo simbólico se encuentran" (pág. 149). Reiterando esa simbiosis del manejo comunicacional, haciendo participe ese componente "mágico" de lo simbólico. Mágico en el sentido que hay poca investigación y su aplicación es limitadamente predecible; al respecto un artículo de comunicación política señalaba, "La sociabilidad es la principal diferencia específica de nuestra especie y para esto ha sido imprescindible el desarrollo de sistemas simbólicos de transmisión de la información (palabras, gestos, imágenes)" (Moreno-Sánchez y Jiménez, 2018, pág. 15). Siendo esta característica el principal argumento para que en periodos cortos se elijan autoridades representativas, en las que el eje ideológico o programático pasa a un segundo plano en el momento que el elector defina sus preferencias. 
En un análisis de la nueva cultura política, denominada así por Barandiarán, Unceda y Peña (2020), decían "estamos en condiciones de reafirmar es la intensa relación e interacción entre la comunicación política y la cultura política, dos conceptos cada vez más vinculados" (pág. 276). Se hace mención a una nueva cultura política fundamentada en el desprendimiento de doctrinas políticas y la mayor participación de movimientos tradicionalmente excluidos, minorías sexuales, pacifistas, ecologistas, etc. También se reconoce el uso de medios de comunicación alternativos en detrimento de los tradicionales medios de comunicación de masas, ello se puede confirmar en la cada vez mayor relevancia que adquieren las redes sociales en las campañas electorales, con los respectivos riesgos y ventajas que ello signifique.

Otras características innovadoras es como señala Laguna (2017), "si en un principio la figura profesional de referencia eran los periodistas, progresivamente se fueron incorporando expertos en marketing y publicidad para, finalmente, desembocar en la figura del Director de Comunicación como profesional más visible de los nuevos tiempos" (pág. 3). Entonces, asistimos a una época en la que la propaganda, entendiendo esta como la difusión de ideas pasa a un segundo plano, y triunfa la lógica de vender un "producto" político-electoral a través de la publicidad y el marketing. Todo lo mencionado se enmarca en el campo de estudio de la comunicación política y necesita ser comprobado a través de la presente investigación.

\section{Método}

El análisis descriptivo aplicado tiene características exploratorias cualitativas entre las organizaciones políticas que lograron representación en el parlamento pervano, a su vez, estudia comparativamente la imagen de los candidatos al Congreso de la República examinando los niveles de articulación entre el símbolo de la organización, la imagen del candidato (sus expresiones y actitudes) y el mensaje manifiesto expresado en el eslogan de campaña.

El universo analizado son todos los partidos políticos participantes en las elecciones extraordinarias al Congreso del Perú realizado el 26 de enero, la muestra examinada son las organizaciones políticas que lograron pasar la valla electoral que según ley No 28617 que a la letra dice "para acceder al procedimiento de distribución de 


\section{8}

escaños del Congreso de la República se requiere haber alcanzado al menos seis (6) representantes al Congreso en más de una circunscripción electoral, es decir cinco por ciento (5\%) del número legal de sus miembros o haber alcanzado al menos el cinco por ciento (5\%) de los votos válidos a nivel nacional" (Resolución N. ${ }^{\circ}$ 015-2011JNE, 2011). A dichas organizaciones con representación congresal se les realizo un seguimiento de manera individual en base a los conceptos señalados: El proceso electoral, el símbolo, la imagen, y la cultura política. A su vez planteamos una articulación que genere proporcionalidad en el uso estético de recursos así como la consistencia de su mensaje (Espí, 2017).

El objetivo de la investigación es explorar la articulación del símbolo, la imagen y la cultura política, expresada en el eslogan de los candidatos, teniendo en cuenta un objetivo de la metodología seguida por Calvo, Campos y Díez, (2019) quienes plantean el objetivo siguiente: "analizar las similitudes y diferencias percibidas por los partidos políiticos en el desarrollo de la campaña" (pág. 128), considerándolos como indicadores propuestos en nuestra investigación. A su vez, se complementó el análisis de imagen con un Delphi con la experticia correspondiente en el manejo de marca.

\section{El lenguaje político}

Considerando al lenguaje como un fenómeno colectivo que tiene su origen en la interacción social entre los seres humanos, como tal está constituido de un dominio consensual (Echevarría, 2006), que va más allá del signo lingüístico a un conjunto de signos y símbolos que en este caso privilegiamos. Por ello, en el análisis de López y Chihu (2011) citan a Edelman (1960), quien establece tres aspectos relevantes en la forma como opera la cultura; el simbolismo, el lenguaje político y el espectáculo político, en este caso el aspecto relevante al que nos referimos es "al lenguaje como una forma muy importante de la política simbólica" (López y Chihu, 2011, pág. 106), más adelante construye un esquema de análisis muy singular en el que "la pasividad política es el resultado de que, sistemáticamente, el proceso político produce satisfacción tangible para determinados grupos sociales, y satisfacción simbólica para otros. La "política simbólica" sería, entonces, las diferentes formas en que los actores y las agencias políticas manejan símbolos para producir "seguridad simbólica" entre grandes masas de individuos aislado e inducir, así, su pasividad 
política" (pág. 105), resulta en ello relevante el rol que tienen en ello los medios de comunicación de masas.

Para entender el lenguaje político en el Perú es necesario conocer a los partidos políticos y la historia de estos tiene algunas características peculiares, una percepción relevante de Tuesta (2005) dice: "la tradición partidaria era otra: clientelismo, populismo, caudillismo; elementos que expresan -de diversas manerasuna carencia de lealtades, organización y maquinaria partidaria" en otro segmento analítico señala que: "Es así que todos los partidos políticos integrantes del abanico del sistema no sólo no pudieron articular demandas, sino que sus adhesiones orgánicas fueron cada vez menores" y a manera de conclusión recalca que: "Todo ello ha traído como consecuencia un sistema de partidos atomizado, compuesto por partidos políticos desarticulados y partidos electorales dirigidos por figuras independientes de diversa calidad que no contribuyen a estabilizar un sistema ni a construir una democracia viable" (págs. 187-189), a todo ello habría que agregarle el agravamiento que se evidencia en la desideologización de gran parte de la sociedad pervana que se expresa en la existencia de agrupaciones políticas sin principios e ideología, carentes de un programa de gobierno que movilice al electorado, asistimos - así - a la personalización y mediatización de la política donde todo gira en torno a la imagen, características y atributos personales del liderazgo político.

Respecto al mismo tema - los partidos políticos - Agustín Haya de la Torre (2004), dice: "La precariedad del sistema de partidos en el Perú se explica por el efecto negativo de las dictaduras y los regímenes autoritarios en la formación de la institucionalidad republicana" (pág. 204). Esa fragilidad del sistema de partidos políticos nos licencia para argumentar su desarticulación simbólica, fortaleciendo la figura del caudillo en la coyuntura electoral. Por su parte Seifert, (2014) señala, "el derrumbe del sistema de partidos, a nivel nacional, en la década de los noventa trajo como consecuencia una alta volatilidad debido a la falta de lealtad partidaria, una fragmentación política con un gran número de partidos políticos que fueron altamente personalistas" (pág. 39), en perjuicio del proceso de institucionalización que aún no se consolidaba. Debemos de recordar que durante el gobierno de Alberto Fujimori, así como al terrorismo de los grupos insurgentes, se buscó responsabilizar de la crisis 


\section{0}

económica, política y moral del país a los partidos políticos tradicionales, este discurso fue asumido por gran parte de la población, y que favoreció a la aparición de liderazgos y movimientos conocidos como "independientes" con un lenguaje político vacío de contenido ideológico.

Además en una perspectiva de liderazgo innovador en el ámbito político, Jiménez, Fernández y Sánchez, (2019) señalan, el surgimiento continuo de caudillos militares o civiles que, personalizan de manera radical las dinámicas políticas y, más allá de sus referentes ideológicos se enmarcan, de una forma $u$ otra, en las categorías de populismo o neo-populismo que afectan de forma negativa a la calidad de las democracias de la región" (pág. 146). Ello porque el caudillo populista busca someter a las instituciones a la "voluntad popular" de una opinión publica orientada y formada a través de los medios de comunicación que - muchas veces - en alianza con el caudillo de turno construyen un sentido común o una hegemonía acorde a sus intereses.

Las características del lenguaje político durante los procesos electorales, es una mezcla de propuestas y descalificaciones donde se resaltan los vínculos cercanos o indirectos con la corrupción de cada político en contienda; el debate programático se debilita, y las características personales terminan - en varias circunstancias monopolizando el debate político; Ruiz en una publicación decía que "hay factores que han influido notablemente en la psicología social. La indignación ciudadana por la conducta de los líderes y sus partidos políticos manchados por la corrupción crearon condiciones electorales adversas para estos. En la lógica social había una predisposición a patear el tablero y por eso, tenemos un alto porcentaje de votos en blanco, viciados y no emitidos, alrededor del 50\% de electores" (Ruiz, 2020). Aunque este no sea el propósito de nuestra investigación resulta influyente en la decisión de los electores, ya que el contexto peruano es particularmente sensible a temas de corrupción y se manifiesta en escepticismo y desconfianza hacia los políticos y la política en general.

\section{La cultura política}

El análisis teórico de la cultura es arriesgado en la medida que la dispersión conceptual es muy heterogénea, sin embargo nos situamos en la perspectiva de 
Geertz (2003) quien en su libro "La interpretación de las culturas" señala que "la cultura denota un esquema históricamente transmitido de significaciones representativas en símbolos, un sistema de concepciones heredadas y expresadas en formas simbólicas por medios con los cuales los hombres comunican, perpetúan y desarrollan su conocimiento y sus actitudes frente a la vida" (pág. 88). En tal sentido, asumimos el criterio de la imagen como elemento representativo de la cultura política actual.

Desde otra perspectiva más audaz de la cultura que encontramos en Castell y Himanen (2016), que señalan que debemos pasar de la cultura de la libertad a la cultura de la creatividad, la misma que le reconoce como: "La cultura de la creatividad y se caracteriza por la idea de que todas las personas debieran tener la oportunidad de realizar su potencial individual en toda su extensión" (pág. 316). A su vez, Hall plantea que, "se puede entender fácilmente por qué sentido, lenguaje y representación son elementos tan críticos en el estudio de la cultura. Pertenecer a una cultura es pertenecer aproximadamente al mismo universo conceptual y lingüístico es saber cómo los conceptos e ideas se traducen a diferentes lenguajes" (Hall, 2010, pág. 450).

Para entender la cultura política peruana habría que tomar una concepción holística de la misma, en la perspectiva de Hume, señala que lo político no tiene autonomía, se subordina a lo social y a lo económico (Ors, 2018), por lo que se hace necesario ir más allá de lo estrictamente político en el afán de consolidar una propuesta integral, más aun si se trata de sociedades como la peruana, donde la política tiene cada vez menos importancia para gran parte de la ciudadanía, ya decía Carlos Piedra Buena en un artículo publicado por la revista Araucaria de que se percibe "un marcado desinterés por la cosa pública, donde la cultura política juega un rol clave (Eberhardt, 2015, pág. 89), esto se grava con el individualismo enraizado en importantes sectores de la población donde las acciones colectivas son poco valoradas.

Por otro lado, Degregori (2013) desde una perspectiva antropológica señala que el proceso de democratización ha sido ampliamente mayoritario -en nuestro país- es decir ha sido masivo, enorme, pero por supuesto que partiendo de una situación tan autoritaria y tan atrasada (pág. 255), en otra perspectiva, las evidencias del análisis 


\section{2}

intercultural de sectores minoritarios es incipiente, al margen que como el caso de la mujeres indígenas mexicanas lograron un gran acercamiento en el ámbito político, Dalton en un publicación científica señala que "Las Imágenes en estas son símbolos que muestran la participación de la mujer mexicana en la revolución y no se menciona si son indígenas o no" (Dalton, 2018, pág. 35).

\section{El rol de los partidos políticos.}

En otra perspectiva de análisis, los partidos políticos se desarrollan a partir de "dos principios fundamentales: la despersonalización de las relaciones políticas y el establecimiento de un programa" (Blitstein, 2018, pág. 179), tal como señala el autor, "En otras palabras, el dang debe reposar sobre la impersonalidad del principio que reúne al grupo. Esa eliminación de los vínculos personales en el nombre y en el discurso de la sociedad no significaba que estos vínculos personales ya no serían necesarios, sino que quedarían necesariamente ocultos" (pág. 180). Los intereses personales y de grupo o las afinidades personales deberían estar supeditadas al interés del partido y sus objetivos, esta visión se debilita en la política peruana, pues la imagen del "líder", es apabullante, incluso el partido y sus objetivos se supeditan el, todos están detrás de la figura del caudillo, quien muchas veces actúa de forma paternalista, sin fortalecer la institucionalidad partidaria, centralizando todo en su persona y entorno más cercano.

Otro detalle significativo en este análisis, es que nuestros políticos como caudillos asumen responsabilidades técnicas de comunicación en el proceso, tal como señala Aira: "Una desproporcionada atribución de responsabilidad, y en este contexto implica que los mismos políticos asuman en nuestro entorno roles que en países como Estados Unidos o Gran Bretaña asumen sistemáticamente profesionales externos a las estructuras tradicionales de los partidos políticos" (Aira x, 2011, pág. 22).

Lo descrito por Aira muestra una de las características de la política peruana en la que se trabaja de forma poco profesional, con "hiperliderazgos" dentro de los partidos, como el candidato o el caudillo que no permiten que funcionen las estructuras partidarias, hace que prime un quehacer espontaneo, que se guía muchas veces por la práctica sin valorar o reconocer la importancia de los datos y 
evidencia, así como un cuerpo teórico que debe de tener una organización política para desarrollar una comunicación política adecuada.

\section{Teorías de la Comunicación Política}

A pesar de que la comunicación política es una disciplina contemporánea, el análisis teórico es todavía limitado, sin embargo, hay autores como López, Gamir y Valera que publicaron un destacado trabajo (2018), donde reconocen las perspectivas de la comunicación política, a partir de investigaciones debidamente argumentadas en las que relacionan tanto la "Agenda Setting" como el "Framing" y que resumimos a continuación.

\section{Modelo de Agenda setting}

Teoría creada por los norteamericanos Maxwell Mc Combs y Donald Shaw en 1972 (Todo Marketing, 2013), ellos consideran que la agenda se divide en tres conceptos dinámicos, la agenda de medios, la agenda del público y la agenda política; la dinámica de estos elementos logra manipular de manera exitosa la opinión pública, consolidando objetivos políticos en el corto plazo. En primer término se establecen los temas que los medios deben tratar, en segundo término de debe interactuar con el público, ya sea con encuestas, foros, consultas previamente monitoreados; y en tercer aspecto es la información que las instituciones gubernamentales quieren informar a la colectividad (Centro Político, 2015). La crítica académica a esta teoría parte del carácter funcionalista y cortoplacista de la propuesta, al margen que su efectividad, no conduce a la consolidación doctrinaria de la propuesta, aunque su aplicación es efectista y puede traer resultados favorables en las campañas electorales. A ello debemos de agregarle la capacidad que ha demostrado en no solo poner en la agenda mediática determinados temas para el debate político, además está logrando determinadas características y atributos a estos temas y a los propios personajes públicos. 


\section{4}

\section{Figura 1}

Agenda Setting

Temas de los medios

Información

gubernamental

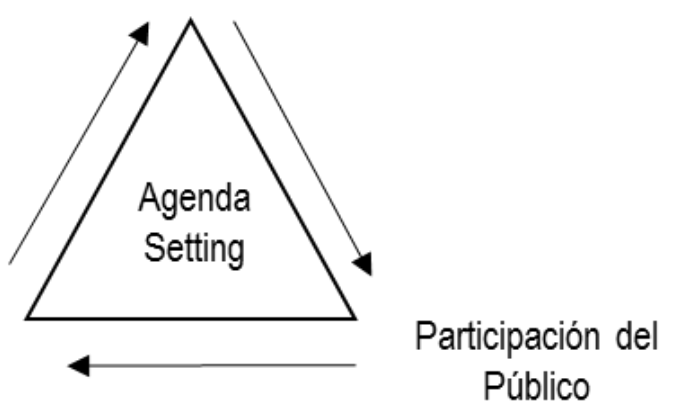

En los tres espacios la decisión del medio es trascendente en el desarrollo de alguna propuesta, si bien son tres entes anexos, funcionan siempre y cuando interactúen de forma sistemática, teniendo una mayor significación el papel de los medios de comunicación de masas, en los que se incluye tanto al sistema convencional como a los medios alternativos (entendiendo esto como lo distinto a lo tradicional).

\section{El Framing}

Es una perspectiva que analiza los encuadres que los medios de comunicación utilizan cuando abordan toda clase de temas y controversias en sus mensajes, tienen un origen inglés, y su consistencia es interdisciplinaria va más allá de la concepción comunicativa; desde la perspectiva psicológica, antropológica y política. Su análisis sustancial está enmarcado en el discurso mediático, sin soslayar el nivel simbólico dentro de un contexto cultural determinado (Lopez, Gamir, y Valera, 2018). En alusión a Entman, consideran que el Framing combina 4 operaciones discursivas. 


\section{Figura 2}

Framing

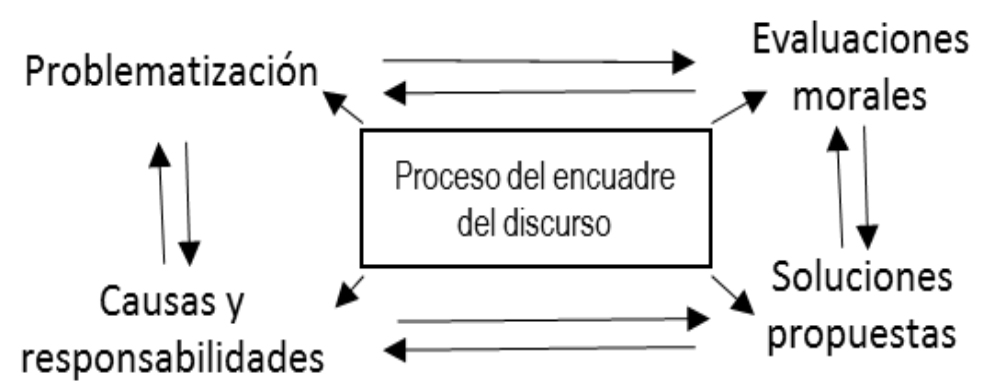

El framing asume criterios de análisis que van más allá de los mensajes, para encontrarse con los mapas cognitivos e imágenes mentales del seudo entorno como lo denomina Rodríguez (2015, pág. 67). Siendo esta una propuesta sustancial en el análisis de las campañas políticas además del aporte significativo de Goffman radica en el encuadre microsociologico de la identidad simbólica, que a su vez va a encuadrar estructuras discursivas culturales en la sociedad, ciertamente parte del análisis psicológico para aportar en la teoría de la comunicación política propiamente.

\section{La Imagen en el proceso electoral}

La precariedad de las identidades políticas se cumple como lo que dijera Bauman, la identidad, la fragilidad y la condición por siempre provisional de la identidad ya no se puede ocultar (Bauman, 2005, pág. 41). En este aspecto esta dado en los hechos, reconociendo que la imagen de los partidos político peruanos ante la opinión publica muestran fragilidad histórica, y como señala Pease y Romero, (2013) "la falta de democracia interna impide que los partidos sean algo más que caudillos con entorno" (pág. 434). Resaltando una vez más la débil imagen que proyectan los partidos en cuanto a su estructura orgánica, que trae como consecuencia la falta de institucionalidad partidaria.

En el análisis teórico "el simbólico social no viene inscrito en un código genético, se lo construye a partir de la relación con lo social y con el sí, lo que permite elaborar 


\section{6}

un conjunto de representaciones que se traducen en normas y valores que dan sentido a la existencia y movilizan hacia la acción" (Suárez, 2003, pág. 76), ello es importante señalar por los cambios que han acontecido en la sociedad peruana en las últimas décadas, transformaciones que guardan relación con procesos como la migración y la extensión de una nueva cultura popular denominada "chicha", que se manifiesta en nuevos símbolos e imágenes que se asocian al ciudadano promedio.

La imagen ayuda a proyectar una idea de fuerza y mística en los electores, ello lo podemos encontrar en un análisis de las campañas donde se afirma que tanto en Argentina como en Brasil en los procesos del 2010 y del 2014, se proyectan imágenes de actos públicos en los que se aprecia organización, y compromiso de militantes y adherentes al proyecto político, ello se puede identificar - que se visualiza - en los segmentos de horario gratuito de propaganda electoral (Rocca y Moscovich, 2018). La "imagen del candidato se aproxima al de "representación cognitiva" se refiere a lo que un individuo cree subjetivamente que es verdadero, constituye una respuesta personal a los símbolos y mensajes políticos que se despliegan en la comunicación de campaña" (Slavinsky, D’adamo y García, 2005, pág. 126). Como señalan otros autores, el objetivo de mostrar una imagen es de influir en la sensibilidad, apelando a las emociones del elector, más allá de que pueda o no representar sus características ideológicas. Los autores recalcan que la función de la imagen durante las campañas es colaborar en la construcción simbólica de autoridad (pág. 128), que resulta siendo fundamental en la construcción del liderazgo caudillista. En la línea de análisis de Bourdieu, viene a ser el elemento de legitimación social del candidato. Sin embargo se debe tener cuidado, en la línea publicitaria, forzando la analogía, puede que anuncios dejen de influir de forma positiva sobre su receptor, llegando incluso a desencadenar algún tipo de respuesta negativa (Sánchez, 1999, pág. 200), la saturación de anuncios publicitarios durante las campañas tiene un resultado contraproducente, generando un efecto no deseado por el emisor del mensaje. A su vez Suárez (2003) recalca que "el sujeto jamás adquiere por completo los elementos impuestos por lo social; más bien los reconstruye, los modifica, los adecua a los nuevos elementos que tiene que enfrentar" (pág. 77), es decir los adapta a su realidad. Construyendo una estructura teórica que va más allá de los 
presupuestos simbólicos de legitimación, sino también de los espacios culturales representados por los condicionamientos cotidianos de los electores, que muchas veces colisionan con las necesidades y los intereses particulares, en la medida que los parámetros o las limitaciones económicas fácticas son más urgentes en las decisiones del día, hay que precisar que una cosa es la imagen proyectada que no necesariamente es la imagen percibida.

\section{Resultados}

En el objetivo de la investigación se plantea identificar los valores relevantes de cada una de las organizaciones políticas y encontrar las relaciones entre los elementos simbólicos representativos, es este caso se tuvo en cuenta el símbolo propiamente, la imagen representativa y el eslogan que identificó a cada organización política, y finalmente se revisó los resultados definitivos publicados por la ONPE, organismo nacional de procesos electorales en Perú.

\section{Tabla 1}

Resultados proceso electorales congresal 2020

\begin{tabular}{|c|c|c|c|c|c|}
\hline Símbolo & Imagen representativa & $\begin{array}{l}\text { Eslogan } \\
\text { Mensaje }\end{array}$ & Votación & $\%$ & Escaños \\
\hline & 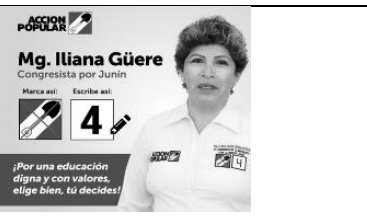 & $\begin{array}{l}\text { Por una } \\
\text { educación } \\
\text { digna y con } \\
\text { valores }\end{array}$ & $1,518,716$ & 10.26 & 25 \\
\hline & Juntos spodemos & $\begin{array}{l}\text { Seguridad y } \\
\text { orden }\end{array}$ & $1,240,716$ & 8.38 & 11 \\
\hline & 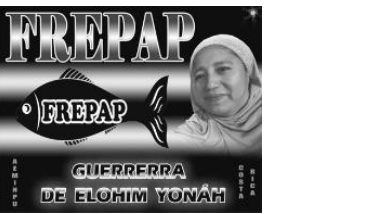 & $\begin{array}{l}\text { integración } \\
\text { territorial y } \\
\text { sudamericana } \\
\text { de las fronteras } \\
\text { vivas del Perú }\end{array}$ & $1,240,084$ & 8.38 & 15 \\
\hline
\end{tabular}




\section{8}

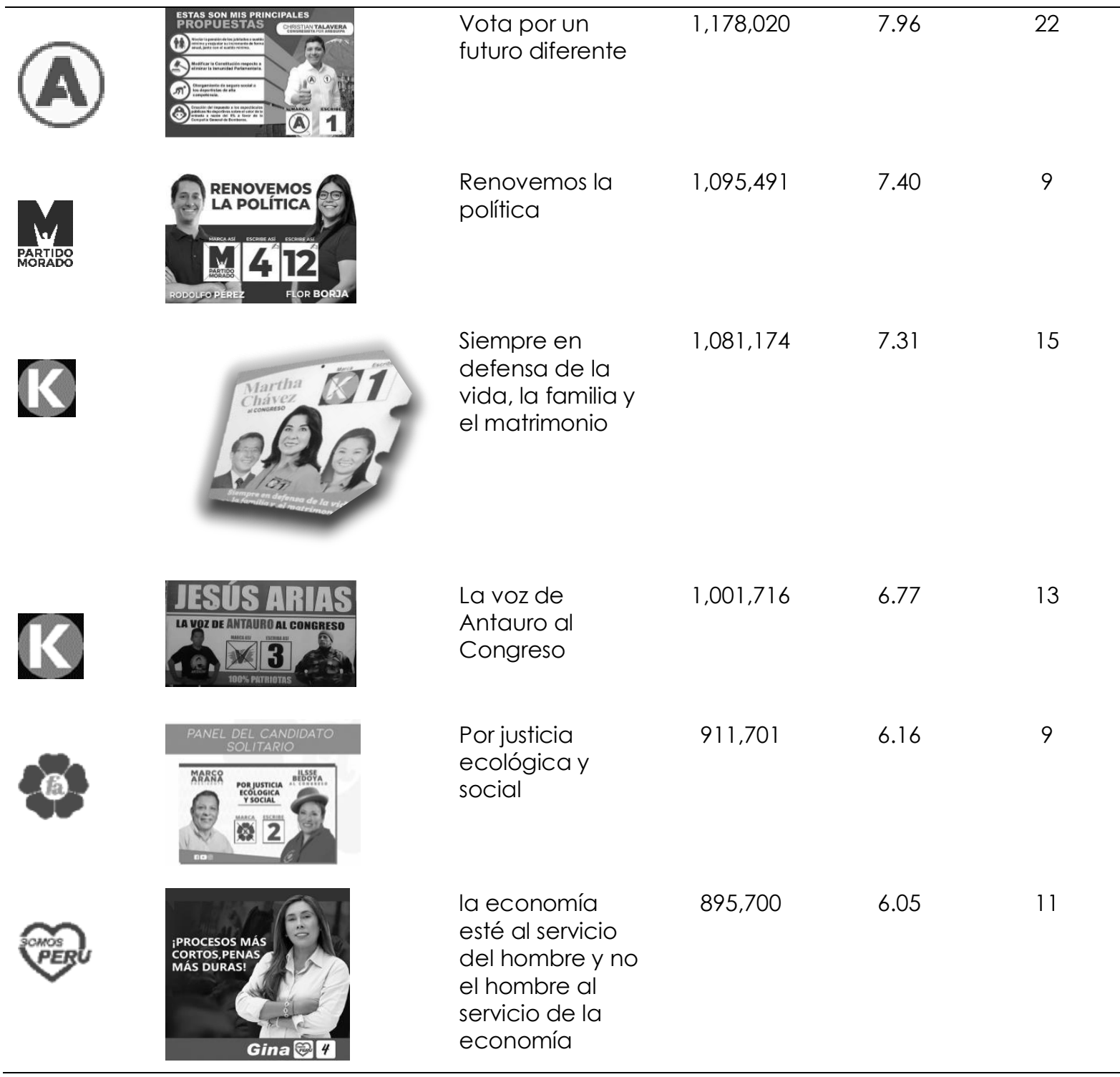

Nota. ONPE, elaboración propia

En una interpretación de los mensajes, Tamayo (2002), dice: "El rostro es primordial en la Comunicación de los estados de emocionales" (pág. 14), se puede asociar ello al predominio de la fotografía con la imagen del candidato que destaca sobre la imagen del símbolos e incluso del mensaje manifiesto del partido, asimismo apela indirectamente al factor emocional con la identificación del candidato y su eslogan como parte de su estrategia, como señala Caramelo (2018) "la comunicación emocional como estrategia de persuasión en el ámbito político actúa de forma positiva en los resultados electorales" (pág. 285). En todas las imágenes presentadas 
la imagen del candidato es la más destacable, aunque no necesariamente los muestra en su mejor performance.

\section{Figura 3}

Relaciones de Imagen, mensaje y símbolo elecciones congresales 2020

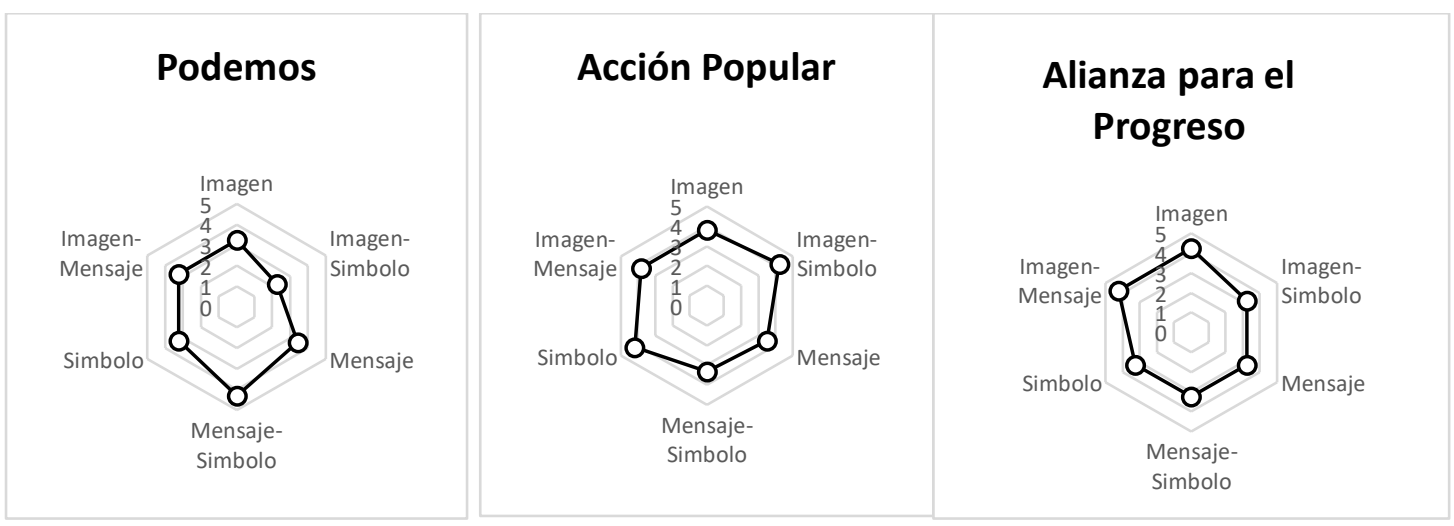

En el trabajo de campo se percibe que es el partido Acción Popular quien tiene el símbolo más reconocido, asimismo la imagen con más alta calificación la presenta el partido Alianza para el Progreso, en lo correspondiente al mensaje, el partido Podemos muestra una calificación más homogénea así como la mejor relación sobre todo con el mensaje. En términos de relaciones de imagen y símbolo, mensaje e imagen; se muestra una muy baja asociación, generando una endeble consolidación relacional. Un detalle que muestra que la propuesta ideológica es menos significativa que la figura del caudillo, peor aún su relación con el símbolo, que es más como elemento que permite cumplir requisitos que representar su propuesta, a ello podemos agregarle que muchos símbolos de campaña han estado relacionados a la figura de los líderes políticos, por ejemplo la O de Ollanta, La K de Keiko o A de Acuña, todos ellos líderes indiscutibles de sus agrupaciones políticas. 


\section{Figura 4}

Relaciones de Imagen, mensaje y símbolo elecciones congresales 2020

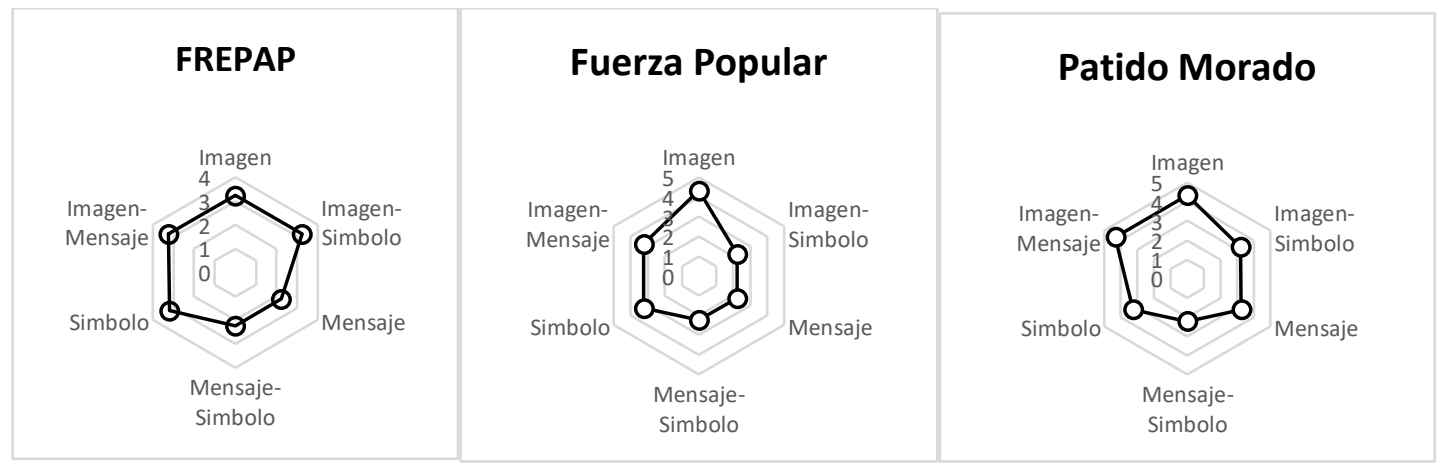

En el análisis relacional de las tres propuestas, si bien no hay desequilibrios significativos, la consolidación del predominio institucional tampoco es destacable, en todos los casos se sobrepone la figura del candidato y el eslogan, no apuestan a la propuesta del partido, menos aún a la ideología, por el contrario esta gira en torno a los atributos y características del líder.

\section{Figura 5}

Relaciones de Imagen, mensaje y símbolo elecciones congresales 2020

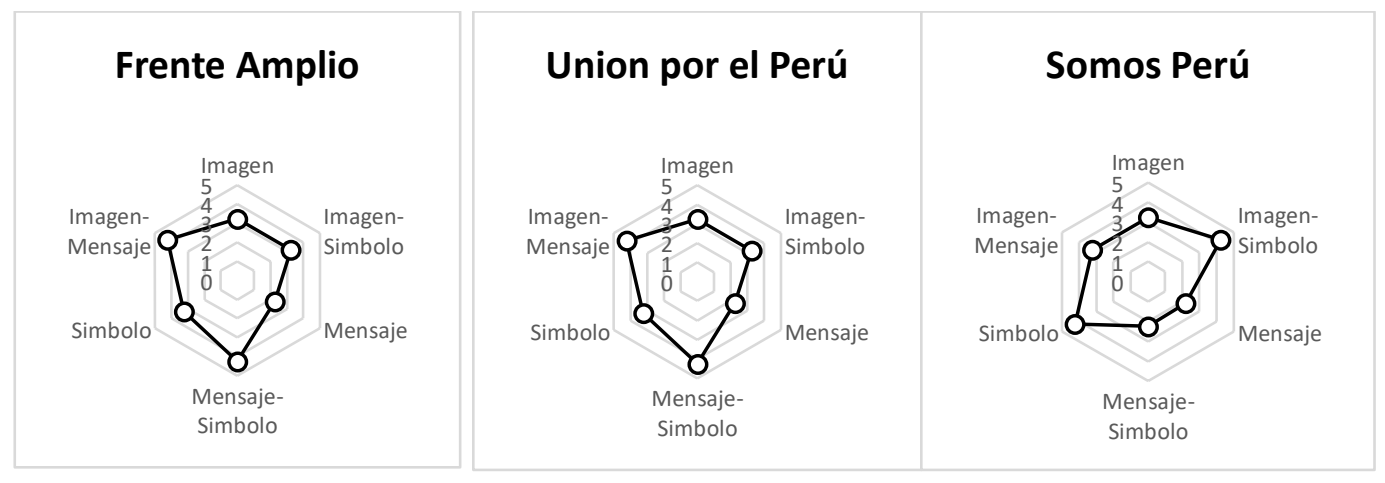


Desde la perspectiva del rostro, como parte determinante en la imagen, Mazzuchini (2019) señala, "Así, no es solo la circulación en sí lo que le permite a la imagen actuar y producir efectos, sino su capacidad para cuestionar o reproducir cierto régimen de lo sensible a partir de su trabajo en un dispositivo producido por diversos activismos artísticos" (pág. 13), hay que entender que todo comunica, es así que los gestos y expresiones del rostro tienen un mensaje hacia los electores.

El rol de la cultura desde una perspectiva de la imagen en el proceso electoral en Arequipa, es una muestra que evidencia el deterioro de las doctrinas, así como el deterioro de la identidad cultural lo que llama Bourdieu la complicidad estructural pre reflexiva, es decir, de manera inconsciente, tanto el candidato como el elector soslayan sus identidades tanto culturales como políticas por una imagen más coyuntural.

Sulmont señala que "el sistema político peruano, si bien ofrece pistas programáticas, no construye vínculos programáticos lo suficientemente fuertes entre electores y políticos, lo que reforzaría la importancia de los vínculos personalistas o carismáticos en la configuración de identificaciones políticas" (2018, pág. 453). Afirmación que hoy se confirma, ya que los vínculos programáticos son casi inexistentes, la militancia partidaria solo funciona para procesos electorales y existe muy poca vida orgánica en los partidos, además del vaciamiento ideológico de los mismos, en los que la palabra o decisiones del líder están por encima de la propia estructura partidaria, incluso del programa de gobierno y hasta de los estatutos que tenga la organización política.

El eslogan de cada partido político que participo en las elecciones del 26 de enero del presente año, representa las características del candidato, ya sea por su trayectoria social y cultural, sin embargo tiene muy poca relación con los postulados de su doctrina política, a su vez, tampoco se aprecia en el eslogan una visión ni regional, ello es importante si consideramos que la región Arequipa es el centro macroregional, tal como señala Cusihuamán, (2019) "la región Arequipa, genera la construcción de vínculos con los grupos étnicos de regiones contiguas, fortaleciendo el liderazgo macro regional, por lo que se hace imprescindible echar una mirada a los diálogos interculturales que aún no se han iniciado" (pág. 350), como se puede visualizar por el contrario se percibe propuestas coyunturales en base a 


\section{2}

características del líder, llegando incluso a mencionarlo junto al nombre de su candidato.

\section{Conclusiones}

En el desarrollo de la investigación se demuestra que hay un deterioro de los logos de los partidos - lo que tradicionalmente generaba identidad en los procesos electorales - el predominio de la imagen del candidato es tan fuerte que resulta intrascendente el logo y en todo el proceso se resalta y posiciona la figura del postulante, ello también guarda relación con nuestros sistema electoral donde la existencia del voto preferencial para elegir a los congresistas promueve lo personalización de la política en detrimento de los partidos o agrupaciones.

Los eslóganes son elaborados en base a las características del líder de la agrupación política, no tienen relación con la propuesta doctrinaria de la organización política ni mucho menos son una visión regional ni nacional, por el contrario las propuestas tienen perspectiva coyuntural, ello expresa la fuerte presencia del marketing político en nuestros procesos electorales.

La imagen más significativa de la campaña electoral que hemos analizado demuestra que en ningún caso resalta la corriente ideológica que abraza la organización políitica, ni el modelo de sociedad al que se aspira, gira en torno a la problemática coyuntural, el corto plazo o lo inmediato, con temas como la seguridad ciudadana, que es un problema importante pero se aborda desde una perspectiva muchas veces superficial y efectista, pero no estructural, a su vez se insiste en el cambio, pero no hay elementos simbólicos que demuestren este cambio, ni tampoco se explica lo que significaría o como se expresaría dicho cambio.

Teóricamente se plantea que la consolidación doctrinaria obedece a que las propuestas políticas están alineadas a una corriente política, la misma que se expresa en sus elementos simbólicos, su eslogan, el logotipo del partido y la imagen más destacable del partido en la campaña electoral, sin embargo se puede plantear una conclusión invertida, señalar que cuando la organización política no tienen una perspectiva política clara, ni un posicionamiento ideológico definido, la relación entre estos elementos no son disfuncionales, por el contrario también muestran 
armonía de desconexión, de manera que en ningún caso se percibe una disfuncionalidad de los elementos simbólicos del partido.

\section{Referencias}

Aira Foix, T. (2011). Arte de la Invisibilidad Terapéutica en Política. (A. c. Politai, Ed.) Politai, 2 (3), 17-28.

Barandiarán, X., Unceda, A., y Peña, S. (2020). Comunicación Política en tiempos de nueva cultura política. Icono 14, 18(1), 256-282. Recuperado de https://iconol4.net/ojs/index.php/iconol4/article/view/1382

Barnhurst , K. (2012). Tendencias de la Comunicación Política: Desafios teóricos y Metodológicos ante la crisis actual. En Estudios de Comunicación Política (V. Sampedro, Trad., Primera Edición ed., págs. 19-44). Chicago, Estados Unidos: Tecnos.

Bauman, Z. (2005). Identidad (Primera edición ed.). España: Losada.

Blitstein, P. (2018). El concepto de "partido político" y los mandarines chinos en el exilio: concepto mandarines chinos en el exilio: concepto. Araucaria: Revista Iberoamericana de Filosofía, Política, Humanidades y Relaciones Internacionales, 20(40), 159-184. Recuperado de https://r.search.yahoo.com/_ylt=AwrEeBmhg3VeRngAfgqnfAx.;_ylu=X3oDMTB yOHZyb21 †BGNvbG8DYmYxBHBVcWMxBHZOaWQDBHNIYwNzcg-$/ R V=2 / R E=1584788513 / R O=10 / R U=h t t p s \% 3 a \% 2 f \% 2 f$ dialnet.unirioja.es\%2fdescar ga\%2farticulo\%2f6844632.pdf/RK=2/RS=X.rbnX1 1 haCr1SRPPVzYulXSELI-

Bourdieu, P. (2007). El Sentido Práctico (Primera edición en Español ed.). Buenos Aires: SIGLO XXI Editores.

Bunker, K., y Bauchowitz, S. (2016). Pronósticos electorales y seguimiento de la opinión pública en América Latinoamérica: una aplicación a Chile. Revista de Ciencia Política, 54 (2), 207-233. Recuperado de https://www.researchgate.net/publication/339677130_Electoral_forecasting_ and_public_opinion_tracking_in_Latin_America_An_application_to_Chile_Revi sta_Politica 


\section{4}

Calvo, D., Campos-Domínguez, E., y Díez-Garrido, M. (2019). Hacia una campaña computacional: herramientas y estrategias online en las elecciones españolas. Revista Española de Ciencia Política(51), 123-154. Recuperado de https://dialnet.unirioja.es/servlet/articulo? codigo=7190506

Caramelo, L. (2020). Análisis del discurso emocional de Donald Trump en la campaña electoral de 2016. Ambitos(47), 267-287. Recuperado de https://dialnet.unirioja.es/servlet/articulo? codigo=7202602

Castells, M., y Himanen, P. (2016). Reconceptualización del Desarrollo en la era Global de la Información (primera ed.). Chile: Fondo de Cultura Económica.

Centro Político. (2015). Agenda Setting, La manipulación política a través de los medios. Recuperado de https://www.centropolitico.org/agenda-setting-lamanipulacion-politica-a-traves-de-los-medios/

Cusihuamán, G. (2019). Culturas invisibles en la educación superior de Arequipa, Perú. Revista de Ciencias Sociales (RCS), XXV(Número Especial 1), 341-353. Recuperado de https://produccioncientificaluz.org/index.php/rcs/article/view/29633

Dalton Palomo, M. (2018). Construcción de ciudadania y paridad de las mujeres indígenas en México. En F. López, P. Olamendi, M. Dalton, D. Recondo, y V. Olmedo, Interculturalidad y justicia electoral. TEPJF.

De la O Támez, K. (2013). Clientelismo Político en México: El bajo Capital Social, los Escasos Recursos y la Desigualdad como variables independientes. En S. Fajuri, G. Martinez, y A. Myers, Democracia y Elecciones (págs. 161-179). España. Recuperado de https://dialnet.unirioja.es/servlet/libro? codigo $=525348$

Degregori, C. (2013). Del mito del Inkarrí al mito del progreso (primera edición ed.). Instituto de Estudios Peruanos.

Eberhardt, M. L. (2015). Democracias representativas en crisis. Democracia participativa y mecanismos de participación ciudadana como opción. Araucaria, Revista Iberoamericana de Filosofía, Política y Humanidades, 17(33), 83-106. Recuperado de http://institucional.us.es/revistas/Araucaria/A\%C3\%B1 o\%2017\%20\%20N\%C2\%B A\%2033\%20\%202015/Democracias\%20representativas\%20en\%20crisis.pdf 
Echevarría, R. (2006). Ontologia del lenguaje (primera edición ed.). Buenos Aires, Argentina: Ediciones Granica S.A. Recuperado de https://books.google.es/books?id=3fhCeuHJl3UC\&printsec=copyright\&hl=es\& source=gbs_pub_info_r\# $v=$ onepage $\& q \& f=$ false

Espí Hernández, A. (2017). Proporcionalidad de los sistemas electorales latinoamericanos: Un estudio comparado de 18 Países basado en resultados electorales dados entre 2010 y 2014 . Revista de Ciencia Política, 55(2), 33-66. Recuperado de https://revistapolitica.uchile.cl/index.php/RP/article/view/53178/55815

Geertz, C. (2003). La Interpretación de las culturas. Barcelona, España: Gedisa S.A. Hall, S. (2010). Sin garantías: Trayectorias y problemáticas en estudios culturales (primera ed.). Perú: Instituto de Estudios Peruanos.

Haya de La Torre, A. (2004). El sistema de partidos políticos en el Perú y la nueva ley. Investigaciones Sociales, 8(13), 207-234. Recuperado de https://revistasinvestigacion.unmsm.edu.pe/index.php/sociales/article/view/6 924

Jiménez, Í., Fernández, C., y Sánchez, Y. (2019). Perfil actitudinal de líderes innovadores: Una mirada desde la psicología política. Revista de Ciencias Sociales (RCS), XXV(3), 140-151. Recuperado de https://produccioncientificaluz.org/index.php/rcs/article/view/27363

Laguna, A. (2017). La profesionalización comunicativa: partidos políticos o empresas de comunicación. Ambitos, 22 (1), 1-10. Recuperado de https://revistascientificas.us.es/index.php/Ambitos/article/view/9950 López Gallegos, A., y Chihu Amparán, A. (2011). Símbolos, lenguaje y espectáculo en la democracia: el escepticismo político de Murray Edelman. Espiral, XVIII(50), 101-139. Recuperado de http://www.espiral.cucsh.udg.mx/index.php/EEES/article/view/1497/1304 Lopez, G., Gamir, J., y Valera, L. (2018). Comunicación política: Teorias y Enfoques (primera ed.). España: Sintesis.

Mazzuchini, S. (2019). Los Usos Políticos de la fotografia en las acciones donde está Santiago Maldonado y Santiago, tu mirada nos mira. Avatares(18). 


\section{6}

Recuperado de

https://publicaciones.sociales.uba.ar/index.php/avatares/article/view/5079

Moreno-Sánchez, I., y Jiménez, J. (2018). Una perspectiva neurobiológica y

comunicacional de la imagen y de la realidad aumentada. Icono 14, 16(1),

1-21. Recuperado de

https://iconol4.net/ojs/index.php/iconol4/article/view/1102

Myers Gallardo, A. (2013). Derrotas electorales: Actitud, conducta y carrera de los candidatos en las elecciones presidenciales en México. En S. Fajuri, G. Martinez, y A. Myers, Democracia y Elecciones (pág. 52). Salamanca: Idemdigital. Recuperado de https://dialnet.unirioja.es/servlet/libro? codigo $=525348$

Ors Marqués, C. (2018). El lugar de Hume en una posible historia natural de las teorias política. Araucaria, 20(40), 333-347.

Pease, H., y Romero, G. (2013). La Política en el Perú del siglo XX. Lima, Perú: Fondo Editorial de la Pontificia Universidad Católica del Perú.

Peña, S. (1995). Rito y Simbolo en la Campaña Electoral para la Alcaldia de Bogotá. Análisis Político(25). Recuperado de https://www.google.com/url? client=internal-element-cse\&cx=partner-pub$3317167162609756: 3134777453 \& q=h t t p s: / / r e v i s t a s . u n a l . e d u . c o / i n d e x . p h p / a n p$ ol/article/view/75673\&sa=U\&ved=2ahUKEwil npuRqaPoAhUKHLkGHeKeD58Q FjAAegQIAhAB\&usg=AOvVaw2FvhZY_z76vw4ex-VCKXLB

Pérez Corti, J. (2018). Democracia, Elecciones y Función Electoral. Revista de la Facultad de Derecho de México, 68 (270), 573-611. Recuperado de http://www.revistas.unam.mx/index.php/rfdm/article/view/63737

Resolución N. ${ }^{\circ}$ 015-2011-JNE (Jurado Nacional de Elecciones 2011 ). Recuperado de https://cdn.www.gob.pe/uploads/document/file/439200/015-2011-JNE.pdf

Rocca Rivarola, D., y Moscovich, N. (2018). Representación visual y simbólica de la militancia en las campañas electorales de Cristina F. de Kirchner (2007 y 2011 ) y Dilma Rousseff (2010 y 2014). Opinion Pública Campiñas, 24 (1), 144-

177. Recuperado de http://dx.doi.org/10.1590/1807-01912018241144

Rodríguez, C. (2015). La teoría del framing aplicada al 'rescate' a España. Marco (Marketing y Comunicación Política), 1, 63-81. Recuperado de Universidad 
de lbagué: https://pure.unibague.edu.co/es/publications/la-teor\%C3\%ADadel-framing-aplicada-al-rescatea-espa\%C3\%B 1 a

Ruiz, M. (2020). SERVINDI Comunidad Intercultural para un Mundo más humano y diverso. Recuperado de https://www.servindi.org/actualidadopinion/30/01/2020/los-resultados-electorales

Sánchez, M. (1999). Eficacia Publicitaria: Teoria y Práctica. Sevilla, España: McGrawHill.

Sartori, G. (201 1). Como hacer Ciencia Política. Madrid, España: Prisa Ediciones.

Seifert Bonifaz, M. (2014). Colapso de los partidos nacionales y auge de los partidos regionales. Pontificia Universidad Católica del Perú. Recuperado de http://escuela.pucp.edu.pe/gobierno/wpcontent/uploads/2015/04/Colapso-de-los-partidos-nacionales-y-auge-de-lospartidos-regionales-M.-Seifert.pdf

Slavinsky, G., D’adamo, O., y García, V. (2005). Comunicación Política y campañas electorales (primera edición ed.). Barcelona, España: Gedisa S.A.

Soní-Soto, A. (201 1). Mitos y Símbolos en la Campaña. Palabra Clave, 14 (1), 67-82. Recuperado de https://palabraclave.unisabana.edu.co/index.php/palabraclave/article/vie $w / 1873 / 2449$

Suárez, H. (2003). La transformación del sentido (Primera edición ed.). Bolivia: Muela del Diablo Editores.

Sulmont, D. (2018). ¿Existe el voto programático en elecciones con un sistema de partidos políticos débil? Un análisis de las elecciones presidenciales peruanas de 2016. Revista de Ciencia Política, 38(3), 429-457. Recuperado de https://scielo.conicyt.cl/scielo.php?script=sci_arttext\&pid=s0718090X2018000300429

Tamayo de Serrano, C. (2002). La estética, el arte y el lenguaje visual. Revista Palabra Clave(7). Recuperado de https://palabraclave.unisabana.edu.co/index.php/palabraclave/article/vie $\mathrm{W} / 404$

Todo Marketing. (2013). Que es la Agenda Setting. Recuperado de http://www.todomktblog.com/2013/05/ques-es-la-agenda-setting.html 


\section{8}

Trad Hasbun, R., y lbinarriaga, J. A. (2010). Sobre la guerra electoral. En J. J. Larrea, \& A. Erbin, Comunicación Política en Latinoamérica (págs. 149-178). Argentina: DIRCOM.

Tuesta Soldevilla, F. (2005). Sistema de Partidos Políticos en el Perú. Recuperado de http://www2.congreso.gob.pe/sicr/cendocbib/con4_vibd.nsf/769BOF24BC77 AA9505257CC2005CFB58/\$FILE/Sistema_de_partidos_pol\%C3\%ADticos_en_el_ Per\%C3\%BA_(Libro).pdf 